\title{
Sustainable, Energy Efficient and Economical Design of Single-Family Dwellings
}

\author{
Roz-Ud-Din Nassar ${ }^{1, *}$, Eka Sediadi $^{2}$, Fathia Elmenghawi ${ }^{2}$ \\ ${ }^{1}$ Department of Civil \& Infrastructure Engineering, American University of Ras Al Khaimah (AURAK), United Arab Emirates \\ ${ }^{2}$ Department of Architecture, American University of Ras Al Khaimah (AURAK), United Arab Emirates
}

Received February 6, 2021; Revised April 7, 2021; Accepted May 16, 2021

\begin{abstract}
Cite This Paper in the following Citation Styles
(a): [1] Roz-Ud-Din Nassar, Eka Sediadi, Fathia Elmenghawi, "Sustainable, Energy Efficient and Economical Design of Single-Family Dwellings," Civil Engineering and Architecture, Vol. 9, No. 4, pp. 1048 - 1056, 2021. DOI: 10.13189/cea.2021.090407.
\end{abstract}

(b): Roz-Ud-Din Nassar, Eka Sediadi, Fathia Elmenghawi (2021). Sustainable, Energy Efficient and Economical Design of Single-Family Dwellings. Civil Engineering and Architecture, 9(4), 1048 - 1056. DOI: 10.13189/cea.2021.090407.

Copyright $\odot 2021$ by authors, all rights reserved. Authors agree that this article remains permanently open access under the terms of the Creative Commons Attribution License 4.0 International License

\begin{abstract}
Large scale construction of housing units and other built infrastructure in the United Arab Emirates (UAE) and other Middle Eastern countries result in consumption of huge quantities of aggregate, water and cementitious materials causing fast depletion of these resources. Extreme weathering conditions, on the other hand, require construction of housing units having energy intensive serviceability resulting into uneconomical construction and operational costs of these housing units. This situation merits developing design and construction techniques of these housing units that are sustainable, energy efficient and economical. This paper suggests innovative design and construction approaches for development of single-family housing units that address these requirements. The suggested techniques incorporate the use of recycled and industrial by-products towards production of green concrete and concrete masonry units (CMU) and an architectural design that is based on the concept of use of optimized space and configuration integrated with use of sun shading devices. Field investigation of the energy efficiency of a housing unit constructed according to the suggested architectural design and construction materials showed considerable savings in cooling load of building in summer when compared with that of a traditional building.
\end{abstract}

Keywords Economical-Housing, Recycled-Aggregate, Energy-Efficient, Sustainability

\section{Introduction}

Providing adequate and suitable housing to every member in society is more than addressing the basic human need for shelter; it is about addressing the comprehensive social, environmental and economic problems. This should be a worldwide priority, particularly in developing countries where the demand on housing is increasingly a burden for the governments of these countries. The increase in urbanization and population growth are the main causes for the increasing need for construction of additional housing units in these countries. It has been estimated that $95 \%$ of the total increase in the world's population in the recent decades happened to be in the developing countries [1-2]. These countries will have over two billion new inhabitants during the following two and half decades. According to the estimates of United Nations by 2030 , the population of developing countries shall reach 7.26 billion compared to the 1.29 billion population of developed countries. Furthermore, the annual increase in population for developing countries shall stand at 1.09\% compared to $0.17 \%$ for developed countries [3]. To accommodate the augmented numbers of the urban population in developing countries, it is important to focus on the provision of economical and sustainable housing infrastructure.

On the other hand, the excessive use of construction materials in the development of built infrastructure, e.g. concrete has been a cause of environmental concerns. The production of one of the main constituent of concrete 
named cement results in emission of huge quantity of greenhouse gases particularly $\mathrm{CO}_{2}$. It has been reported that the production of each ton of cement results into emission of about one ton of $\mathrm{CO}_{2}$ to the atmosphere [4-7]. Globally, cement production accounts for $5-7 \%$ of the total anthropogenic $\mathrm{CO}_{2}[8]$. The use of secondary cementitious materials, such as fly ash, silica fume, milled waste glass and ground granulated blast furnace slag as partial replacement of cement in production of concrete and mortars with excellent strength and durability characteristics is now an established fact $[4,9,10]$. When used as partial replacement of cement these materials result in production of economical concrete / mortar having enhanced strength and durability.

As one of the developing countries, the UAE has witnessed significant economic and urbanization growth during the last few decades [11]. As a result there is concern about the impact of this accelerated urban development on the environment. Federal and local governments in the UAE acknowledge the importance of sustainable development approach that affects almost all of the country's sectors, particularly construction industry. Consequently, the goal has been set to enforce building regulations aimed at increasing building energy efficiency and sustainability. Accordingly, the objective of this paper is to suggest sustainable design solutions in terms of placement and architecture of housing complexes, arrangement of the house spaces, and use of energy efficient and environmentally-friendly construction materials to help achieve the comprehensive governmental goal.

Literature identifies the main areas related to the design of dwellings that potentially contribute to the provision of adequate and sustainable housing units in developing world. Bruen, et al [12] assert that the use of suitable design and material selection, as well as the use of proper innovative technology peculiar to developing world, are two important focus areas. Hillier [13] reports that architectural design affect the built environment and at the same time influences the users who experience it. Moreover, since the built environment offers conditions and possibilities for human activity, it is vital to utilize the architectural design as a means to integrate humans and buildings within a "socio-technical system" [14]. Architectural design also affects the building energy performance [15]. The major aspect in architectural design is the space layout, which is the arrangement of different living spaces inside the building according to the placement of interior partitions and exterior walls [16]. Hence, function allocation, space form and dimensions (width, length, and height), as well as the placement of interior and exterior openings are important design variables for space layout design. Taking all these variables into account while designing low-cost housing will not only promote the functionality of the usable spaces, but will also enhance their energy efficiency. Attempts to address the immediate need for housing should concurrently address the long term environmental, economic and social sustainability of the communities they are intended to serve [17]. Similarly, to mold the infrastructure construction into an environmentally friendly and economical development, it is required to make use of recycled materials and various industrial by products towards production of concrete which is considered as one of main construction materials. The use of recycled aggregate as partial replacement or complete replacement of virgin aggregate and partial replacement of cement with secondary cementitious materials such as fly ash have been reported to be excellent techniques of reducing the carbon footprints of construction industry while making it an economical business [18 - 22].

The increasing demand for housing imposes an urgent need to search for new design approaches and use of alternative materials for construction of housing infrastructure [23]. Additionally, appropriate development approaches and technologies common in the west are not always applicable in other contexts and if not implemented correctly, may result in failure. Thus, new comprehensive approaches that take into account the vast context of the developing world should be adopted [24]. Local conditions should be one of the main factors determining the use of appropriate technology in the housing design and choice of materials $[23,25]$. Researchers have outlined a number of barriers that prevent implementing sustainable construction methods in developing countries. Some of these barriers are comprehensive and policy-driven and others are specific to the implementation of the construction [26-27]. The three comprehensive obstacles that have been identified, firstly; environmental sustainability is not prioritized in these countries, secondly; lack of a holistic sustainable design approach which incorporates the social, cultural, economic and environmental aspects of sustainability, and thirdly; the lack of illustrative examples of the best sustainable construction approaches. Lack of introduction of cost effective construction technologies, and the increasing rates of building materials are the other barriers.

The shortage of economical housing in developing countries is of a huge-scale. The growth in the demand of housing has paralleled the high costs and slowness of conventional construction techniques. Building low cost houses is important for a wide range of reasons. The most fundamental factor, which is of economic importance, is that housing is considered the largest expenditure item in the budgets of many individuals and households [28]. Architects and engineers have a challenging role in creating innovative housing designs that have lower construction costs and acceptable living standards to address the continuously increasing demand for such dwellings. Suitable architectural and structural design coupled with innovative construction techniques are among the viable strategies employed in bringing down the 
cost of housing. Use of technological advancement, passive architectural design approaches and durable construction materials are key instruments in the provision of low-cost housing units. Furthermore, it is important to investigate the potential implementation of sustainable methods to economical housing in both developed and developing countries [23].

\section{Research Significance}

Huge quantity of construction materials such as aggregate, cement, and CMU are consumed towards large scale construction of housing units in the UAE and other Middle Eastern countries. Furthermore the operational cost of existing housing units is quite high due to the higher level of energy consumption for cooling of these units during summer. This paper proposes the use of innovative design and construction considerations for adequate low-cost, energy efficient and sustainable single-family dwellings, in order to meet current shortages in the economical housing population. The use of recycled aggregate concrete and $\mathrm{CMU}$ produced with partial replacement of cement with fly ash supplemented with the use of efficient architectural design techniques proved to be viable solutions in the field-tested project for the economical and green construction practices of single-family housing units. If implemented commercially, the suggested design and construction techniques will positively impact the construction industry in the UAE and Middle East.

\section{Method and Materials}

\subsection{Materials}

Two types of concrete mixtures were considered and

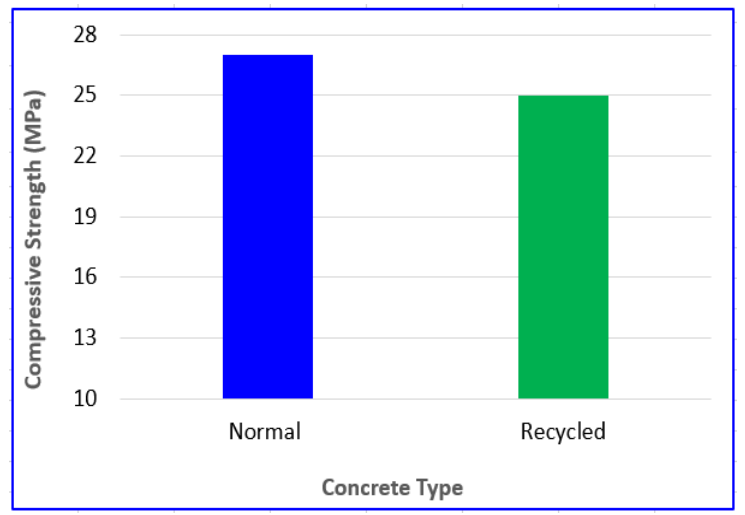

(a) produced in this research program. One with normal aggregate while the second type with $100 \%$ replacement of normal aggregate with recycled aggregate. In both concrete mixtures ordinary Portland cement was used as binder and desert sand was used as fine aggregate. Both mixtures were produced according to the guidelines of ACI 211.1 (Standard Practice for Selecting Proportions for Normal, Heavyweight, and Mass Concrete). These concrete mixtures were produced for a target compressive strength of $25 \mathrm{MPa}$ which is considered a suitable strength for most of the reinforced concrete members made of normal strength concrete. Table 1 shows the composition of the two types of concrete mixtures.

Table 1. Mix proportions of concrete mixtures

\begin{tabular}{|c|c|c|}
\hline Mix designation & $\begin{array}{c}\text { Normal } \\
\text { Concrete }\end{array}$ & $\begin{array}{c}\text { Recycled Aggregate } \\
\text { Concrete }\end{array}$ \\
\hline $\begin{array}{c}\text { Normal aggregate } \\
\left(\mathrm{kg} / \mathrm{m}^{3}\right)\end{array}$ & 738.65 & 0 \\
\hline $\begin{array}{c}\text { Recycled aggregate } \\
\left(\mathrm{kg} / \mathrm{m}^{3}\right)\end{array}$ & 0 & 677.56 \\
\hline Sand $\left(\mathrm{kg} / \mathrm{m}^{3}\right)$ & 585.67 & 585.67 \\
\hline Cement $\left(\mathrm{kg} / \mathrm{m}^{3}\right)$ & 402.56 & 402.56 \\
\hline Water $\left(\mathrm{kg} / \mathrm{m}^{3}\right)$ & 175.35 & 196.45 \\
\hline Admixture $(\%)$ & 0.31 & 0.31 \\
\hline
\end{tabular}

Standard concrete cylinder specimens having diameter of $100 \mathrm{~mm}$ and height of $200 \mathrm{~mm}$ were produced from both types of concretes, cured in lime saturated water and tested in compression at 28-days of concrete age. Disc specimens having thickness of $50 \mathrm{~mm}$ cut from these cylinders were used for water absorption test of the two types of concretes. Figure 1 shows the results of 28 -days compressive strength and 21-days cumulative water absorption carried out at 28 days of concrete age, for the two types of concrete mixtures.

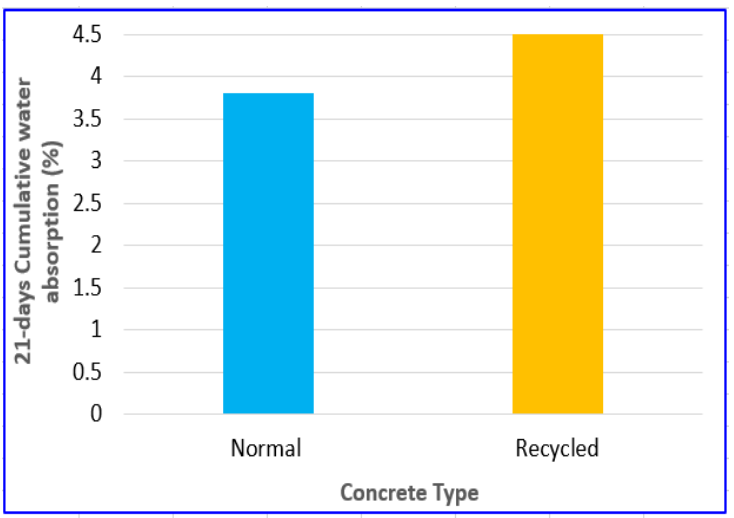

(b)

Figure 1. Concrete mixtures test results: (a) compressive strength $(b)$ water absorption 
Similarly, two types of concrete masonry units (CMU) were produced in the test program. Normal CMU were manufactured with ordinary Portland cement while the fly ash based CMU were produced by replacing $30 \mathrm{wt} . \%$ of cement with class-F fly ash. All test in this experimental program were carried out according to the provisions of the relevant ASTM specifications. Figure 2 shows different views of typical CMU produced using fly ash as partial replacement of cement. Figure 3 shows the compressive strength and water absorption test results of normal and that of fly ash based CMU.

\subsection{Architectural Design Characterization}

Architectural design for an economical house having covered area of $60 \mathrm{~m}^{2}$ is suggested in this work. The house's layout and spatial design shown in figure 4 is suitable for a family that consists of average four members (parents and two children). The main components of this house are: living and dining area, two bedrooms, kitchen, bathroom and a balcony, all of which are architecturally arranged to ensure two main principles; functionality and design efficiency. Space arrangement is a vital consideration in the process of architectural design process.

Spaces are organized according to the standards that fulfil users' activities and social values [29]. Attempt has been made to efficiently incorporate minimum functional areas of the house components in the design. A central living area $\left(\sim 20 \mathrm{~m}^{2}\right)$ is linked directly to the kitchen $(\sim 8.5$ $\left.\mathrm{m}^{2}\right)$ and the bathroom $\left(\sim 3.5 \mathrm{~m}^{2}\right)$ to reduce the circulation area. The openness of the main living area gives the family a place for socialization and eating. The living area is also linked to the bedrooms $\left(\sim 10 \mathrm{~m}^{2}\right)$ and $\left(\sim 9.5 \mathrm{~m}^{2}\right)$ to maintain efficiency in circulation. However, one of the bedrooms is placed closer to the kitchen and the bathroom for privacy purposes to be more suitable to parents.

Additionally, the design efficiency has been achieved by placing the wet areas (kitchen and bathroom) close to each other to reduce the level of plumbing work and drainage. A balcony has been included in the design to provide the residents with an open space for social and hygienic purposes.

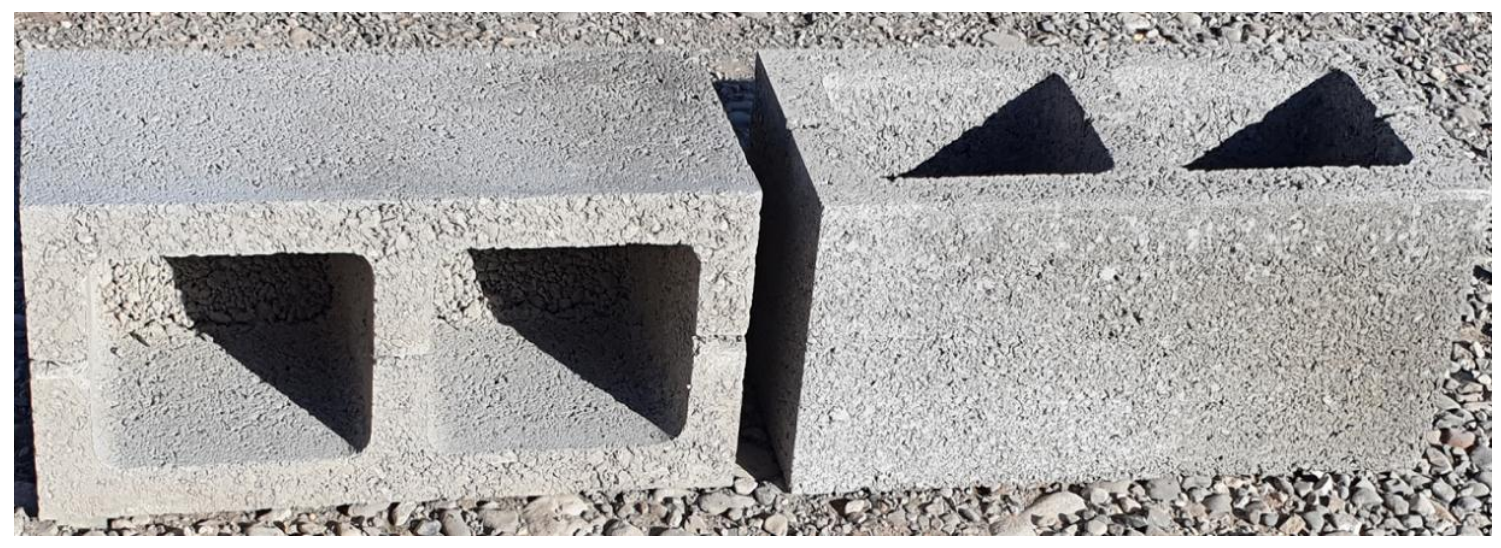

Figure 2. Views of hollow CMU units produced with fly ash as partial replacement of cement

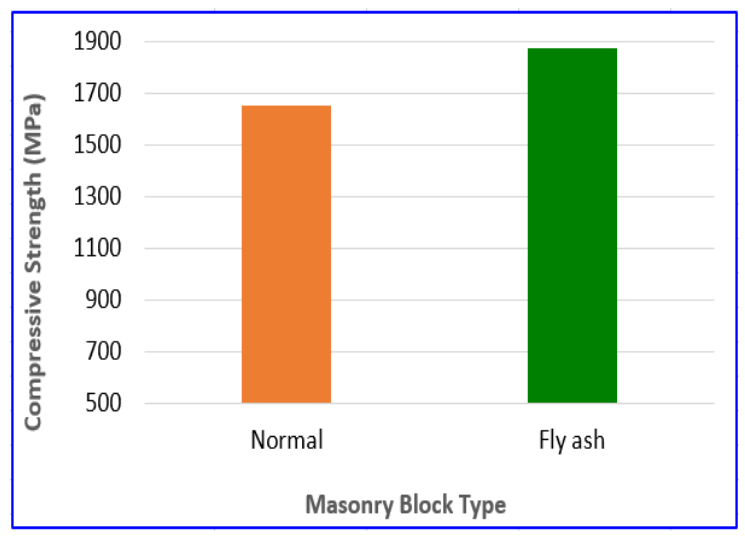

(a)

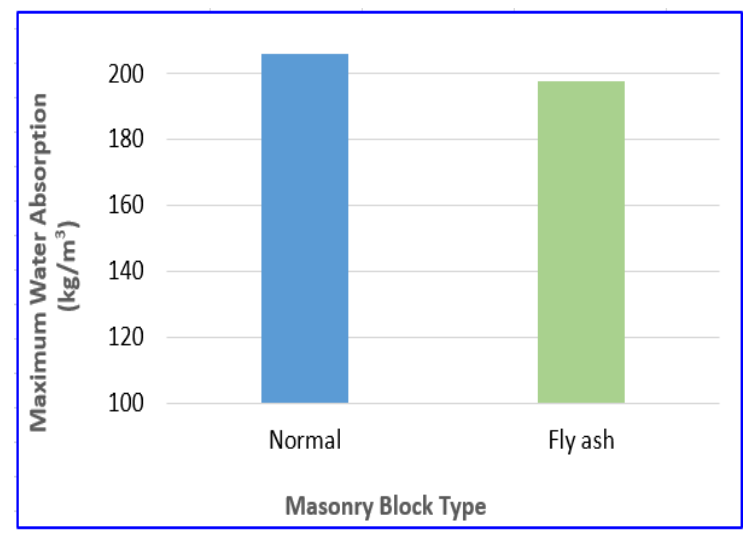

(b)

Figure 3. CMU test results: (a) 28 days compressive strength (b) water absorption 


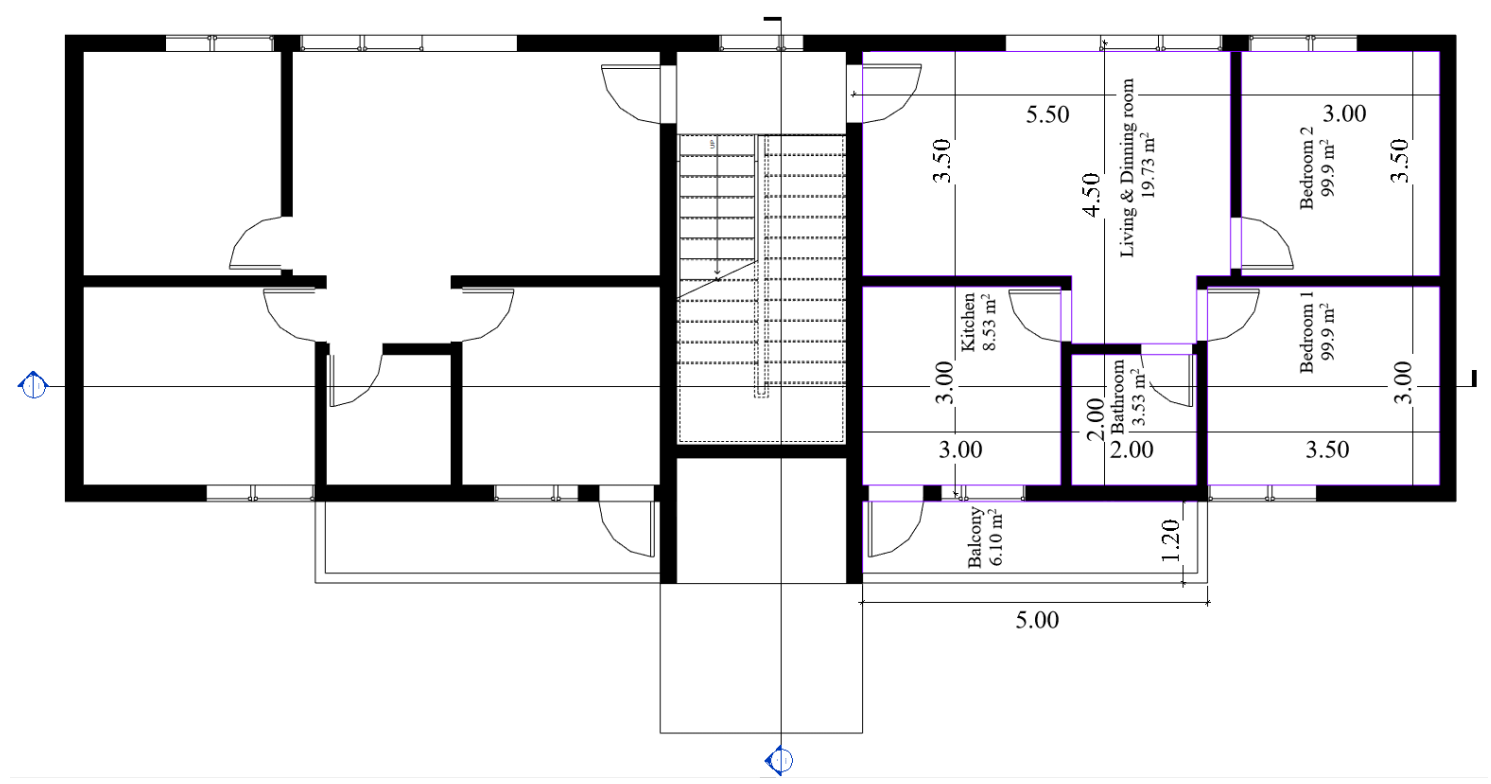

(a)

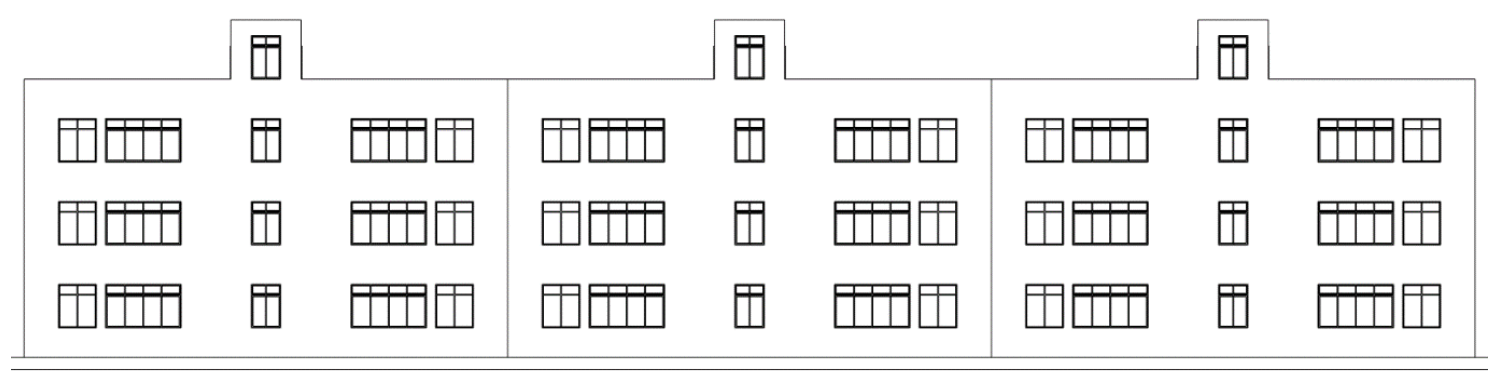

North Elevation Scale 1:100

(b)

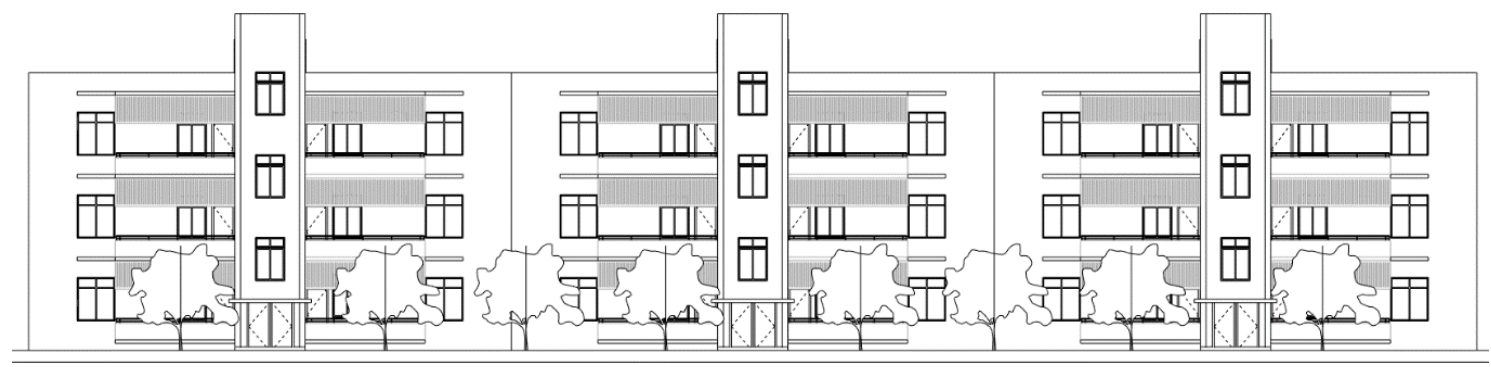

South Elevation Scale 1:100

(c)

Figure 4. Proposed architectural design: (a) plan (b) North elevation (c) South elevation

\subsection{Sustainable Architectural Design Approach}

A housing unit embodying energy efficiency in its design, incorporating recycled materials for its construction, and having compatibility to the natural and built environment surrounding it is termed a sustainable housing unit. Functional comfort and meeting the users' requirements are its other aspects. The essential elements that affect housing design are: location, climate, technology, and users' (local) culture. The sustainable architectural concept should deal with these elements in a sensitive and accurate way to ensure the sustainability of the house itself and the environmental balance.

In the sustainable architecture design approach, the focus is on implementing the passive design approach, suiting the building and its local environmental character [30]. In this case, an attempt has been made to adopt such a passive design that matches the sun path, and the sun's position throughout the year in such a way that reduces the indoor solar heat gain. The sun path diagram analysis can help determine the building openings' orientation to reduce solar heat gain. Additionally, it helps to determine the 
spaces' for natural daylighting. Table 2 shows the result of the sun path diagram simulation of the sun's yearly Azimuth and altitude at noontime in June, March, September, and December in the UAE.

Based on the yearly sun path analysis of the UAE $\left(25.56^{\circ} \mathrm{N} ; 55.89^{\circ} \mathrm{E}\right)$, the position of the sun at noontime happens to be inclined to the south part of a building (figure 5a) pointing at the suitability of the design. Based on the yearly sun's position presented above, in an effort to reduce the indoor solar heat gain, sun shading devices have been added to the building openings. Although the type and the form of these shading devices depend on the orientation of the space, a well-known tool used for this purpose in the middle-east region, the Mashrabiya is placed on the south façade (Figure $5 \mathrm{~b} \& \mathrm{c}$ ).

In the morning hours, the low sun's position starts from sunrise until $8.00 \mathrm{am}$, while in the afternoon, it starts from $4.00 \mathrm{pm}$ until sunset. The north façade receives direct sunlight only during early morning and late afternoon in May, June, July, and August. For the rest of the period, the north façade receives only diffuse lighting. Foregoing analyses suggest the building to have most open side facing north, which receives the least sun's radiation and hence low solar heat gain. To extend the concept of passive design, landscape has been added that surrounds the building (figure 4c). Trees with full leaves block the low direct sunlight coming to the building, especially from the east, west, or south.

\section{Results and Discussions}

\subsection{Test Results of Concrete and CMU}

Concrete compressive strength test results in figure 1a show that compressive strength of recycled aggregate concrete is less than that of normal concrete. Reduction in compressive strength of recycled aggregate concrete is caused by weak mortar / paste clinging to the surface of the recycled aggregates. However achieving $25 \mathrm{MPa}$ compressive strength is good enough for its use in construction of most of the structural members of a reinforced concrete structure. Figure 1b shows that recycled aggregate concrete has higher cumulative water absorption when compared with that of normal concrete. In this case too, the higher water absorption of recycled aggregate concrete can be attributed to the porous old mortar / paste attached to the surface of the recycled aggregate. This is a weak phase as compared to the solid aggregate and new mortar / paste and hence results into somewhat inferior performance of the recycled aggregate concrete. Results plotted in figure 3 shows excellent performance of fly ash based CMU as compared to that of the normal CMU. The improvement in strength and water absorption of the fly ash based CMU is brought about by the pozzolanic reaction of fly ash with the hydrates of cement resulting into formation of additional strength governing hydrated compounds. Such a reaction caused by the presence of fly ash refines the pore structure of the hydrated cement phase and improves the matrix of the concrete by reducing its porosity. Thus the inclusion of fly ash significantly enhances the performance of masonry block in terms and strength and durability. It is to be stated that reduction is water absorption points at enhancement of the long term durability of CMU.

Table 2. The yearly sun positions in the UAE

\begin{tabular}{|c|c|c|c|}
\hline Date / Month & $\begin{array}{l}\text { Time/ } \\
\text { hours }\end{array}$ & $\begin{array}{c}\text { Sun's } \\
\text { Altitude } \\
\text { (degree) }\end{array}$ & $\begin{array}{c}\text { Sun's } \\
\text { Azimuth } \\
\text { (degree) } \\
\end{array}$ \\
\hline \multirow{3}{*}{ 23rd June } & $08.00 \mathrm{am}$ & 35 & 78 \\
\hline & $\begin{array}{c}12.00 \mathrm{pm} \\
\text { (noon) }\end{array}$ & 88 & 178 \\
\hline & $04.00 \mathrm{pm}$ & 37 & 280 \\
\hline \multirow{3}{*}{$\begin{array}{c}\text { 23rd } \\
\text { March/September }\end{array}$} & $08.00 \mathrm{am}$ & 28 & 104 \\
\hline & $\begin{array}{c}12.00 \mathrm{pm} \\
\text { (noon) }\end{array}$ & 65 & 170 \\
\hline & $04.00 \mathrm{pm}$ & 28 & 255 \\
\hline \multirow{3}{*}{ 23rd December } & $08.00 \mathrm{am}$ & 14 & 125 \\
\hline & $\begin{array}{c}12.00 \mathrm{pm} \\
\text { (noon) }\end{array}$ & 40 & 180 \\
\hline & $04.00 \mathrm{pm}$ & 15 & 234 \\
\hline
\end{tabular}




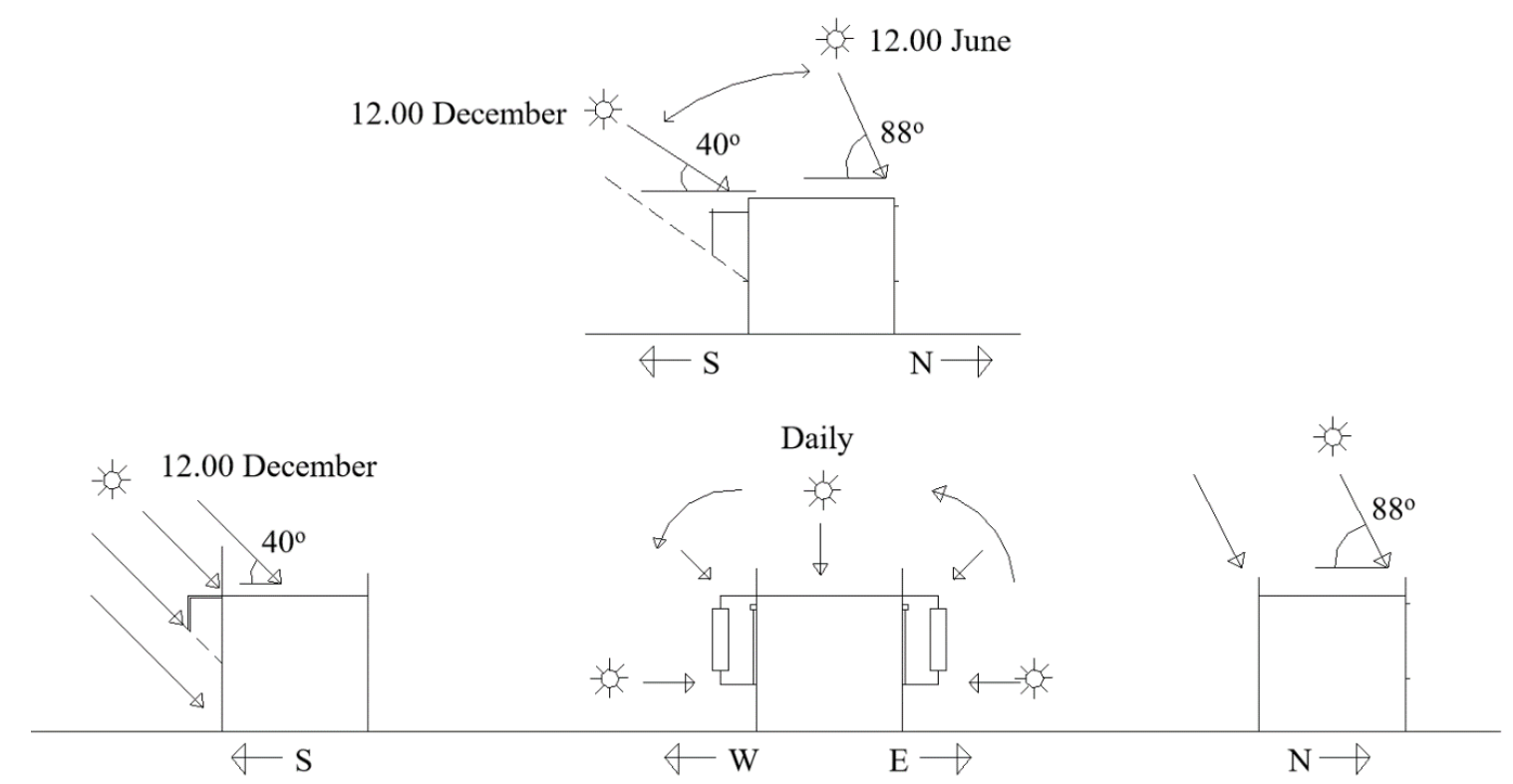

(a)

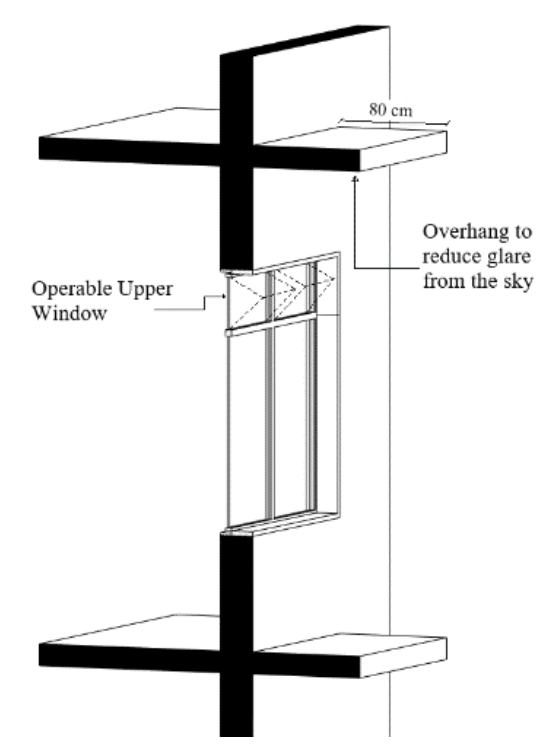

(b)

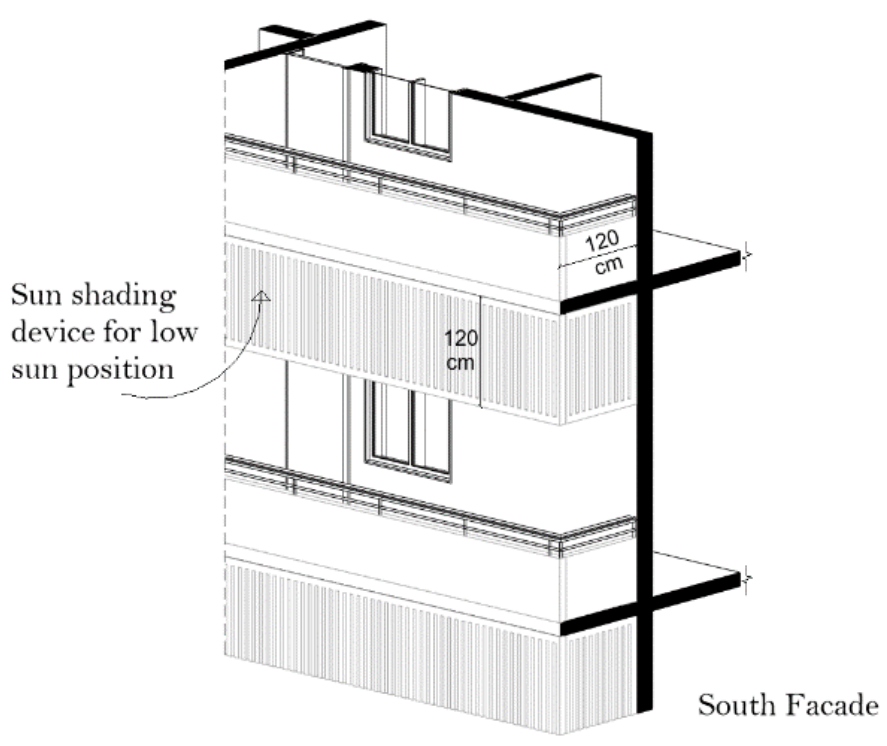

(c)

Figure 5. (a) Sun path in the UAE (b) overhanging shading device (c) vertical shading device

\subsection{Field Investigation Project}

The above stated architectural and material design characteristics were tested in field in pilot project. Two buildings comprising of part of the dwelling plan presented in figure 4 were constructed and evaluated for energy efficiency in the field. Buildings were suitably instrumented and tested for short-time evaluation of the design techniques. Building 1 comprised of traditional construction material and layout having same covered area as that of building 2 which was constructed using the recycled aggregate concrete, fly ash based CMU and the proposed architectural lay out.

Two air conditioners with each having 2-Tons capacity were installed in living room of each of the buildings. In door temperature was monitored six times a day i.e., at 8:00 am, 10:00 am, 11:00 am, 1:30 pm, 4:00 pm, and 7:00 pm. The instruments in each of the buildings' rooms comprised of three thermometers. One of which was installed at $0.5 \mathrm{~m}$ above the floor, second one at mid-height of the room and the third one $0.5 \mathrm{~m}$ below the ceiling. Temperature monitoring was carried out from 15 July to 20 July. Figure 6 presents the plot of the average indoor temperatures of the two buildings.

As can be seen in the figure, building 2 constructed with the recycled aggregate concrete and fly ash based CMU and the proposed architectural design had significantly cooler indoor temperature when compared with traditional 
building (building 1). Plots of figure 6 show that at all times of the day, building 2 was cooler than building 1 at the same cooling effort. The better cooling and hence enhanced energy efficiency of the building 2 is brought about by the passive architectural design approach, material efficiency and improved layout of the building. Above gains point at the energy efficiency, economical living and sustainability of the proposed architectural and material design.

\subsection{Economical Construction}

The use of recycled aggregate for production of recycled aggregate concrete and fly ash as partial replacement of cement towards manufacturing of CMU is not only a practice in line with principles of sustainability but is also aimed at economical construction. These attributes are brought about by the value-added use of waste material (recycled aggregate) and industrial by product (fly ash). Rate analysis of the two types of concrete mixtures based on the local market prices showed that as per the mixture design presented in Table 1 , recycled aggregate concrete happens to be 7 to $8 \%$ cheaper than the conventional concrete. Similarly, CMU produced with fly ash as $30 \mathrm{wt} . \%$ replacement of cement were assessed to be 25 to $30 \%$ cheaper than normal CMU produced in the local market. These analyses suggest significant gains in terms of economizing the construction of housing units if adopted on commercial level.

\subsection{Limitations of the Study}

Although the suggested design provides economical, sustainable, and efficient solution for the construction of single-family swellings, it has its limitations. For example, the suggested design is not viable for tall buildings. Similarly, the temperature test data is valid for UAE and similar environments. Furthermore, observation of this study may considerably vary in case recycled aggregate concrete is replaced with normal weight concrete.

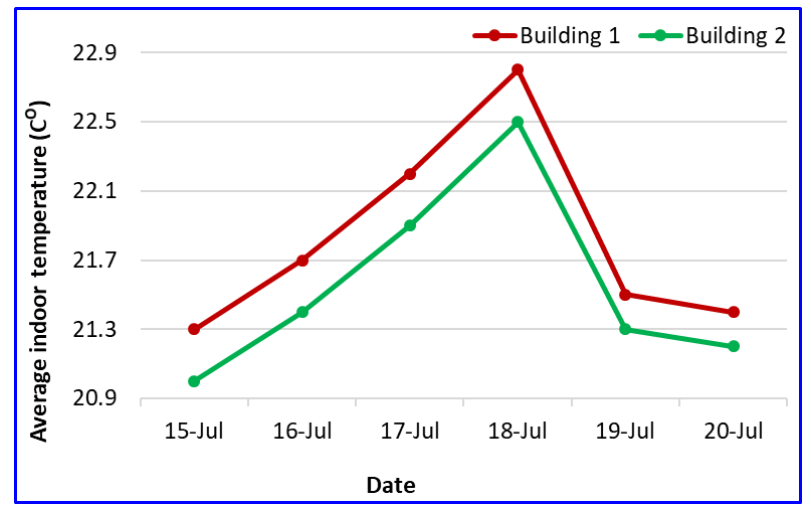

Figure 6. Comparison of indoor cooling of the two buildings

However, with appropriate variations in the design and material choices, the results of this study have the potential to be considered in the other cases including the one's described in the above lines.

\section{Conclusions}

Following conclusions are drawn from this study:

1) The use of recycled aggregate concrete and fly ash-based CMU in the construction of the suggested single-family dwelling is a practice aimed at economical construction and green building construction practices, meeting the requirements of sustainable design. The use of these construction materials yield important energy and environmental benefits.

2) The strength and durability attributes of recycled aggregate concrete satisfy the requirement of normal strength concrete used in construction of building infrastructure. CMU produced with fly ash as partial replacement of cement have been found to have superior strength and lower water absorption when compared with CMU produced with conventional cementitious material. These results point at the enhanced durability of fly ash-based CMU which will result into longevity of service life of masonry structure made of such CMU.

3) Efficient arrangement of minimum functional areas of the proposed single-family housing unit not only addresses all the requirements of a modern single-family housing unit, it also is an economical design solution.

4) The concepts of passive design and sustainable architectural incorporated in the proposed design of single- family housing units excellently suit the local environment of UAE in terms of energy efficiency and user comfort.

5) Field study of the proposed materials and architectural design of the single-family units showed that it is an efficient design that results into considerable saving of cooling energy and hence will prove to have economical living cost.

6) It is to be noted that the conclusions drawn in this study are subject to the limitations described in section 4.4 above.

\section{REFERENCES}

[1] Walker, R. J., Population growth and its implications for global security, Wiley online library 2016, available at https://doi.org/10.1111/ajes.12161, accessed Jan 12, 2021

[2] PRB, 9 Billion World Population by 2025, Population Reference Bureau, 2000, available at https://doi.org/10.1111 /ajes.12161, accessed Jan 12, 2021.

[3] United Nations, Department of Economic and Social Affairs 
Population Division, World Urbanization Prospects, New York, 2019, available at https://population.un.org/wup/Publi cations/Files/WUP2018-Report.pdf, accessed on Feb 2, 2021.

[4] Mehta, P.K., Monteiro, P.J.M, Concrete: Microstructure, Properties, and Materials. Fourth ed., McGraw Hill Education; 2014; New York.

[5] Jieru Zhang, Gengyuan Liu, Bin Chen, Dan Song, Jing Qi, Xinyu Liu, Analysis of $\mathrm{CO}_{2}$ Emission for the Cement Manufacturing with Alternative Raw Materials: A LCA-based Framework, Energy Procedia, Volume 61, 2014, Pages 2541-2545,

[6] Matalkah, F., Alomari, A. H., Soroushian, P., Scaled-up production of alkali-activated cement in the presence of carbon dioxide for concrete construction, Case Studies in Construction Materials, Volume 13, 2020, e00463

[7] Costa, F. N., Ribeiro D.V., Reduction in $\mathrm{CO}_{2}$ emissions during production of cement, with partial replacement of traditional raw materials by civil construction waste (CCW), Journal of Cleaner Production, Volume 276, 2020,123302,

[8] Geng, Y., Wang, Z., Shen, L., Zhao, J., Calculating of $\mathrm{CO}_{2}$ emission factors for Chinese cement production based on inorganic carbon and organic carbon, Journal of Cleaner Production, Volume 217, 2019, Pages 503-509

[9] Neville, A. M., Properties of Concrete, $5^{\text {th }}$ edition, Pearson Education Limited; 2012; Harlow, United Kingdom

[10] Mindes, S., Young, J. F., Darwin, D. Concrete, $2^{\text {nd }}$ edition, Prentice Hall, 2002

[11] World Economic Situation and Prospects, United Nations, 2020. Available at https://www.un.org/development/desa/dp ad/wp-content/uploads/sites/45/WESP2020_Annex.pdf. Accessed on Feb 02, 2021.

[12] Bruen J., Hadjri K., and von Meding J. Design Drivers for Affordable and Sustainable Housing in Developing Countries. Journal of Civil Engineering and Architecture; 2013; 7(10); 1220- 1228.

[13] Hillier, B. Space is the Machine. Cambridge University Press; 1996; Cambridge.

[14]Ekholm, A. The System Man-Building; Problems of Constancy and Change; 31st Annual Meeting of the International Society for General Systems Research, Budapest; 1987; 1.

[15] Pacheco, R., Ordóñez, J., and Martínez, G. Energy efficient design of building: A review. Renew. Sustain. Energy; 2012; 16; 3559-3573.

[16] Du, T., Jansen, S., Turrin, M. \& Dobbelsteen, A. Effects of Architectural Space Layouts on Energy Performance: A Review, Sustainability; 2020; 12, 1-23.
[17] Shelter Initiative for Climate Change Mitigation. Un-Habitat (2008) Shelter Initiative for Climate Change Mitigation (SICCM). Retrieved from https://www.yumpu.com/en/docu ment/read/22138554/low-cost-sustainable-housing-materials -building-technology-in- Accessed October 5, 2020.

[18] Nassar, R., Soroushian, P., strength and durability of recycled aggregate concrete containing milled glass as partial replacement for cement, Construction and Building Materials, Vol. 29, 2012, pp. 368-377,

[19] Nassar, R., Soroushian, P., Ghebrab, T., Field investigation of high-volume fly ash pavement concrete, Resources, Conservation and Recycling, Vol. 73, 2013. Pp. 78-85,

[20] Nassar, R., Soroushian, P., Green and durable mortar produced with milled waste glass, Magazine of Concrete Research, Vol. 64 Issue 7, July 2012, pp. 605-615

[21] Nassar, R., Soroushian, P., Use of milled waste glass in recycled aggregate concrete, Proceedings of the Institution of Civil Engineers - Construction Materials, Vol. 166 Issue 5, October 2013, pp. 304-315

[22] Singh, N., and Nassar, R. Microstructural Characteristics and Carbonation Resistance of Coal Bottom Ash Based Concrete Mixtures, Magazine of Concrete Research, https://doi.org/1 0.1680/jmacr.20.00125, Jan 2021

[23] Sullivan E, Ward P.M. Sustainable Housing Applications and Policies for Low-income Self-Build and Housing Rehab, Habitat International; 2012; 36; 312-323.

[24] Guy, S. Cultures of architecture and sustainability, Building Research \& Information; 2005; 33(5); 468-471.

[25] Ebsen, C. Rambol, B. International review of sustainable low-cost housing projects, Proceedings of Strategies for a Sustainable Built Environment; Pretoria; 2000; 23-25.

[26] Wells J., Population, settlements and the environment: The Provision of organic material for shelter, Habitat International; 200519 (1), 73-90.

[27] Ali, H. H., Alkayed, A. A., Constrains and barriers of implementing sustainability into architectural professional practice in Jordan, Alexandria Engineering Journal, Vol. 58, Issue 3, 2019, pp. 1011-1023

[28] Quigley, J. M., Raphael S., and Rosenthal L. A. Local Land Use Controls and Demographic Outcomes in a Booming Economy, Urban Studies; 2004; 41(2); 389-421.

[29] Mzoori, F. A. Spatial Configuration and Functional Efficiency of House Layouts. LAP LAMBERT Academic Publishing; 2014.

[30] Howard, B., Green Building (A primer for Builders, Consumers and Realtors) building; Environmental Science and Technology (B.E.S.T.); 2003; 5.4 (www.nrg_builder.co $\mathrm{m} /$ greenbld). 